\title{
INFERIOR ALVEOLAR NERVE INJURY ASSESSMENT AFTER SURGICAL REMOVAL OF MANDIBULAR THIRD MOLAR.
}

\footnotetext{
1. BDS, MSc Registrar Admin OMFS Liaquat University Hospital Hyderabad.

2. BDS, FFDRCS (IRELAND), FDSRCS (UK),

MFDRCS (IRELAND), MFDRCS (UK) Consultant Oral \& Maxillofacial Surgeon

Govt. Lady Reading Hospital, Medical Teaching Institution Peshawar.

3. BDS

Postgraduate Trainee

Operative Dentistry

Institute of Dentistry, LUMHS, Jamshoro.

4. BDS, MSc (OMFS)

Lecturer Oral \& Maxillofacial Surgery LUMHS.
}

Correspondence Address:

Dr. Salman Shams

B 1/2 Sajjadabad Society Near Citizen

Colony Hyderabad

salman_omfs@hotmail.com

Article received on:

19/03/2019

Accepted for publication:

27/05/2019

\begin{abstract}
Abdul Wahid Bhangwar ${ }^{1}$, Muhammad Irfan Khan ${ }^{2}$, Hira Fatima ${ }^{3}$, Salman Shams
\end{abstract}
ABSTRACT... Objectives: To assess the nerve injury (inferior alveolar nerve) after surgical removal of mandibular third molars under local anesthesia. Study Design: Observational study. Setting: Oral \& Maxillofacial Surgery Department LUMHS Jamshoro/Hyderabad. Period: From $11^{\text {th }}$ November 2015 to $10^{\text {th }}$ May 2016. Material \& Methods: This study consisted of one hundred patients. Inclusion criteria's were patients with impacted mandibular third molar, patient's age from 18 to $45 y$ ears and irrespective of gender. Exclusion criteria were patients younger than $18 y$ rs of age of above 45 years, patients having neurological disorders, medically compromised patients, patients receiving radiotherapy or chemotherapy, patients with known allergy to local anesthesia, patients having pathology due to mandibular third molars, patients radiographicaly root is very near to inferior dental canal. Results: Out of 100 patients incorporated in this research 66 were male $(66 \%)$ and 34 female $(34 \%)$. The mean age was $29+3.20$ years. Common indication of extraction were recurrent pericoronitis 52(52\%) cases followed by deep caries/ pulpitis in $28(28 \%)$ cases, orthodontic reason in $11(11 \%)$ cases and caries to adjacent tooth in $9(9 \%)$ cases. Third molar impaction according to winter's classification were Mesioangular in $54(54 \%)$ cases followed by Horizontal in $26(26 \%)$ cases and Vertical in $11(11 \%)$. Radiographic showed Narrowing of root in $21 \%$ cases and narrowing of inferior dental (ID) canal $20 \%$ cases, followed by diversion of ID canal in $16 \%$ cases, deflection of root $14 \%$ cases and darkening of root in $11 \%$ cases. After surgical removal of mandibular third molar, the inferior alveolar nerve injury was observed in 6(6\%) cases. Conclusion: We conclude that inferior alveolar nerve paresthesia occurs in $6 \%$ after surgical removal of mandibular third molars.

Key words: $\quad$ Dental Caries, Indication, Pericoronitis, Surgical Extraction, Third Molar.

Article Citation: Bhangwar AW, Khan Ml, Fatima H, Shams S. Inferior alveolar nerve injury assessment after surgical removal of mandibular third molar. Professional Med J 2020; 27(3):530-534. DOI: 10.29309/TPMJ/2020.27.3.3425

\section{INTRODUCTION}

Impaction is the stoppage of absolute eruption into a standard purposeful position of one tooth within precise instance due to lack of room in the dental arch caused by hindrance of another tooth or maturity in an uncharacteristic position". ${ }^{1}$

Maxillofacial surgeons routinely carry out minor oral surgical procedures, the removal of wisdom is also one of them. ${ }^{2,3}$ "Ninety percent of people have at least one impacted wisdom tooth". ${ }^{4}$ Most mandibular third molar extractions are carried out without intra- or post-operative difficulties, but sometimes severe complications may also occur, like pain, trismus, dry socket, infection, hemorrhage, sensory nerve damage (Inferior Alveolar Nerve, Lingual Nerve), and damage to adjacent second molar". 2,4,5

Before procedure radiographic evaluation has been considered as an important factor to predict possible IAN (Inferior Alveolar Nerve) injury during surgery. ${ }^{6}$ Orthopentogram (OPG) and periapicalx-rays are complementary radiographs taken before procedure for evaluation of degree of surgical difficulty, third molar morphology and position, operative risk and proximity to adjacent vital structures, such as Inferior Alveolar Nerve. Certain radiographic signs in OPG mostly show inferior alveolar nerve damage, advance knowledge about the third molar position is very essential before planning the surgical procedure. ${ }^{6}$

The Inferior Alveolar Nerve runs in ID (Inferior 
Dental) canal which is usually near to apices of mandibular third molar, if third molars are impacted so their roots are present close to nerve. ${ }^{7,8}$

On routine clinical examination impacted mandibular third molar are commonly seen and they are in close relation to the lingual and inferior alveolar nerve, during surgical extraction these nerves can be damaged. ., $^{9,10}$

In a literature review seven radiographic indicators of a close relationship between inferior dental canal and impacted third molar are observed, four signs are seen in the root of tooth (darkening, deflection, narrowing and bifid root apex) and the other three are seen in inferior dental canal (diversion, narrowing and interruption in the canal). ${ }^{10}$ Generally during surgical removal of mandibular third molars temporary Inferior Alveolar Nerve injury observed $0.5 \%$ to $7 \%$ and permanent $0.4 \%$ to $0.6 \%$ depending on surgeon skills. ${ }^{10,11}$

Inferior Alveolar Nerve may be traumatized during surgical procedures carried out for the management of trauma, cyst, tumors, preprosthetic problems, placement of dental implants and most commonly surgical removal of lower third molars. ${ }^{12}$

Most cases of nerve injury during surgical subtraction of lower third molars are not identified at the time of surgery, but in the postoperative period on third, fifth and seventh day, patients will be asked about numbness of lip. ${ }^{9}$

\section{Data Collection Procedure}

The study was performed after the permission of ethical committee of hospital and written knowledgeable approval for the study was obtained from the patient. Every patient was explained in their own language about possible outcomes of surgery, preoperative predictive variables were recorded with data record of name, age, gender, residence, type of impaction, using OPG and intraoral periapical radiographs. Classification of third molar used were Pell and Gregory and winter criteria.
Angle formed between the intersected longitudinal axes of mandibular molars (second and third) was the main determent for angulation of mandibular third molar i.e in winter classification. Pell and Gregory classification system was used for classification on basis of level (depth) of impaction. Relationship to the occlusal surface of the neighboring second molar and their arrangement according to anterior limit of the ramus of the mandible was the criteria used here for assessment of impacted teeth."

Surgical procedure were done under local Anesthesia (Xylocaine 2\% with adrenaline), flap was made with surgical blade no 15 and the bone removal was done with the help motor driven surgical bur (Stain less steel straight fissure and round bur) under constant irrigation of normal saline. Suturing was done by using vicryl 3-0."

At the postoperative visits on 3rd, 5th and 7th day of surgery, each patient was asked for dissimilarity in sensation of lower lip and chin between operated and unoperated sides." Tests like two point discrimination test, pin prick test (PP), and light touch assessment test was performed on each patient before and after procedure on their follow up visits at the time of suture removal.

\section{RESULTS}

66 male (66\%) and 34 female patients (34\%); with male to female ratio of 1.9:1 were found in this study (Table-I).

There was variation of age ranging from a minimum of 18 years to 45 years. The mean age was $29+3.20$ years (Figure-1).

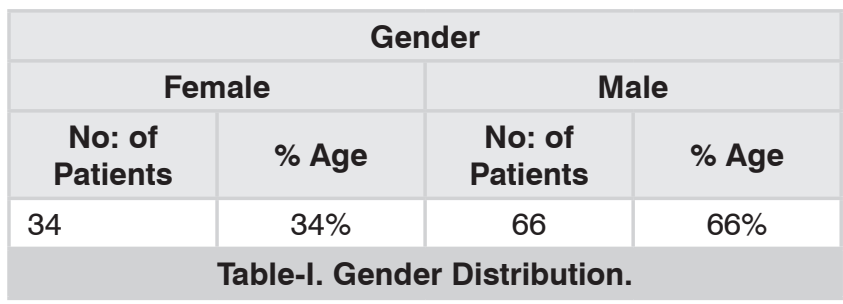

Male: Female Ratio $=1.9: 1$ 


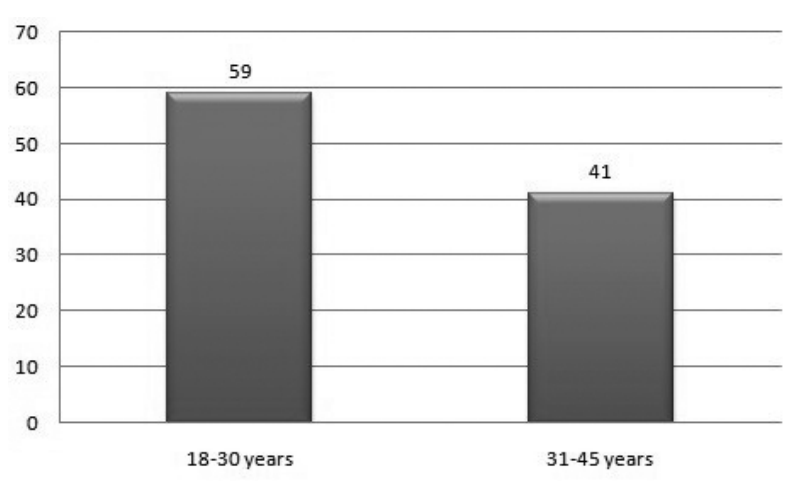

Figure-1. Age distribution.

In our study mostly common indication of extraction were recurrent pericoronitis in 52(52\%) cases followed by deep caries/ pulpitis in $28(28 \%)$ cases, orthodontic reason in $11(11 \%)$ cases and caries to adjacent tooth in $9(9 \%)$ cases. (Figure-2).

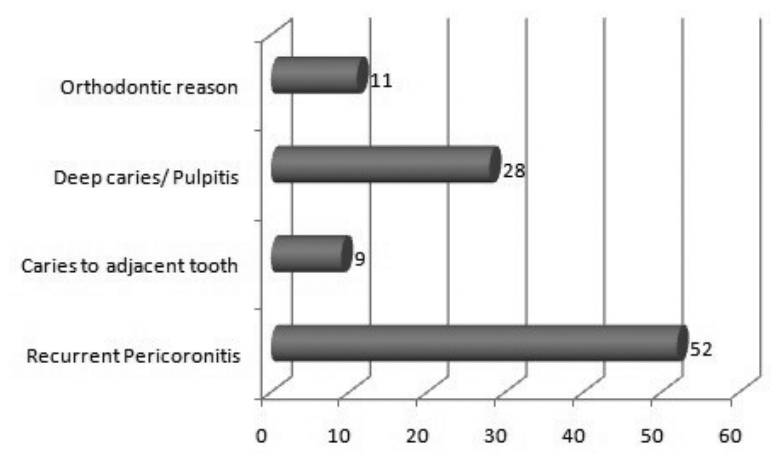

Figure-2. Indication of extraction.

In our study third molar impaction according to winter's classification were Mesioangular in $54(54 \%)$ cases followed by horizontal in $26(26 \%)$ cases and vertical in 11(11\%) (Table-II).

\begin{tabular}{|l|c|c|}
\hline $\begin{array}{c}\text { Third Molar } \\
\text { Impaction }\end{array}$ & $\begin{array}{c}\text { No. of Patients } \\
(\mathbf{n = 1 0 0 )}\end{array}$ & Percentage (\%) \\
\hline Horizontal & 26 & $26 \%$ \\
\hline Mesioangular & 54 & $54 \%$ \\
\hline Distoangular & 9 & $9 \%$ \\
\hline Vertical & 11 & $11 \%$ \\
\hline Table-II. Third molar impaction according to winter's \\
classification.
\end{tabular}

In our study class wise distribution of impacted teeth according pell and gregory classification were Class 1 in $42(42 \%)$ cases followed by Class 2 in 49(49\%) cases and Class 3 in 9(9\%) (Figure-3).

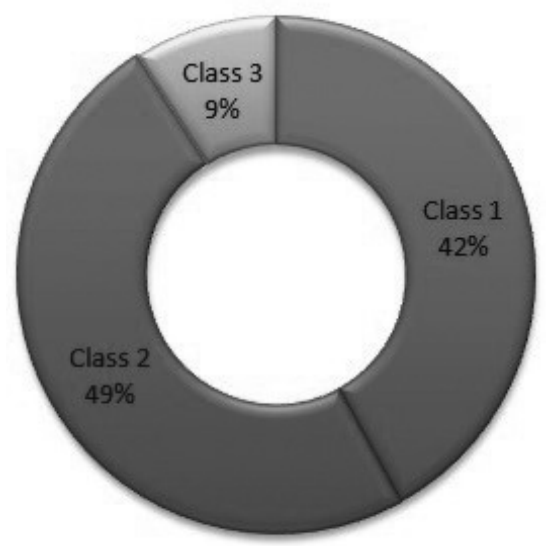

Figure-3. Impacted teeth according pell and Gregory classification.

In our study inferior alveolar nerve injury was observed surgical removal of mandibular third molars in 6(6\%) cases (Table-III).

\begin{tabular}{|l|c|c|c|}
\hline \multicolumn{2}{|c|}{ Yes } & \multicolumn{2}{c|}{ No } \\
\hline $\begin{array}{c}\text { No: of } \\
\text { Patients }\end{array}$ & Percentage & $\begin{array}{c}\text { No: of } \\
\text { Patients }\end{array}$ & Percentage \\
\hline 6 & $6 \%$ & 94 & $94 \%$ \\
\hline \multicolumn{2}{|r|}{ Table-III. Inferior alveolar nerve injury. } \\
\hline
\end{tabular}

\section{DISCUSSION}

It was observed in the current study that out of 100 patients included in this study 66 were male $(66 \%)$ and 34 female (34\%); with male to female ratio of 1.9:1. However study of Thomas Schneider ${ }^{13}$ reported that male to female ratio was 1.04:1 which is lower from this study. In the present study, a minimum of 18 years to 45years. The mean age was $29+3.20$ years, whereas maximum number of cases was seen in $3^{\text {rd }}$ and $4^{\text {th }}$ decade. In the study conducted by F. EzoddiniArdakani ${ }^{14}$ reported that age range was $15-63$ years with a mean age of 26.5 years."

The American Association of Oral and Maxillofacial Surgeons (AAOMS) have set the contributing risk factors that can be helpful in taking decision that when and which way to go for surgical removal. ${ }^{15}$ AAOMS and other health care systems have suggested that underlying pathology, infection 
and harm to adjacent structures as the indications for absolute removal. ${ }^{15,16}$

But here pericoronitis $52 \%$ was the chief reason of extraction of the third molar; that follows occurrence of caries (28\%). These statistics are very much comparable to outcomes acquired in studies by Abdulai $A . E$ et al that shows almost $49.25 \%$ surgical extractions were carried out due to severe pericoronitis and $26.12 \%$ due to caries. ${ }^{17}$ In a Nigerian study repeated pericoronitis happening in comparatively younger age was also the key reason for surgical withdrawal of impacted third molars. ${ }^{18 "}$

Factors which may affect the probability of nerve damage occurring is the depth of the impacted mandibular third molar and its lingual angulation. In our study third molar impaction according to winter's classification were Mesioangular in $54(54 \%)$ cases followed by Horizental in 26(26\%) cases and Vertical in 11(11\%) cases. However in the study of Vikas Sukhadeo Meshram reported considering angulation of third molars in our case series, teeth with mesial angulations were reported in $42.1 \%$, horizontal angulation in $25.1 \%$, vertical angulation in $24.4 \%$ and disto angulation in $6.8 \%$, one case each of lingual version and inverted is also noted. ${ }^{12}$

As we have said that there is elevated discrepancy in IAN/third molar relationship, so to lessen the risk of postoperative dysaesthesia a thorough pre-operative radiographic estimation is requisite to spot the position (buccal, lingual or inferior) and rough calculation of mandibular canal to third molar. ${ }^{19,20}$ In our study radiographs mostly showed narrowing of root in $21 \%$ cases and narrowing of ID canal $20 \%$ cases. Followed by diversion of ID canal in $16 \%$ cases, deflection of root $14 \%$ cases and darkening of root in $11 \%$ cases. However study of Koong reported radiolucent band $54(75 \%)$ cases, thrashing of mandibular canal border $55(76 \%)$ cases, and change in mandibular canal direction 67 (93\%) cases, narrow root 40 (56\%) cases, deviated root $48(67 \%)$ cases, bifid apex 39 (54\%) cases, superimposed $22(31 \%)$ cases and others $3(4 \%)$ cases."
The incidence of neurosensory impairment ranges from $0.35 \%$ to $8.4 \%$, which is one of the complication after wisdom tooth removal..,21,22 In 2013, Smith ${ }^{23}$ produced a clinical study on 1000 patients and he removed 1589 impacted mandibular third molar teeth. Of the 1589 mandibular third teeth taken out, 466 confirmed a far-off connection of their apices to the mandibular canal, 869 were close to the canal, and only 254 were deemed to be quite near to the canal by radiographic confirmation. Postoperatively, in 40 extractions 39 patients account neurosensory trouble over the distribution of the IAN nerve. Seven patients sustained everlasting sensory loss. Horizontal impaction pattern showed larger percentage of nerve damage that is $4.7 \%$ while vertical pattern encountered least which is only $0.9 \%$. In our study IAN injury was encountered post surgically in (6\%) cases."

\section{CONCLUSION}

This study concludes that there are chances of inferior alveolar nerve injury after surgical removal of mandibular third molar i.e about $6 \%$. Further, by reviewing this study dentist can establish the risk/ benefit ratio before surgical removal of impacted mandibular third molar teeth.

\section{Copyright $@ 27$ May, 2019.}

\section{REFERENCES}

1. Sesic S, Prohic S, Komsic S. Incidence of impacted mandibular third molars in population of Bosnia and Herzegovinia: A retrospective radiographic study. J.Healt sci. 2013; 3:151-158.

2. Shams S, Hassan SG, Punjabi SK, Abdullah S. Molar Caries; Distal surface mandibular second molar caries, existence and association with partially erupted mandibular third molar. Professional Med $\mathrm{J}$ 2017; 24(7):1088-92.

3. Contar CMM, Oliveira PD, kanegusuku k. Complications in third molar removal: A retrospective study of $\mathbf{5 8 8}$ patients. Med Oral Cir Bucal. 2010 Jan 1; 15:74-78.

4. Gisakis IG, Palamidakis FD, Farmakis ET. Prevalence of impacted teeth in a Greek population. J of Inve and Clin Dent 2011; 2:102-109.

5. Hassan SG, Shahzad M, Mirza D. Wisdom tooth removal: Are we following any guidelines in Pakistan. Med Forum 2013; 24:27-30. 
6. Wildson CG, Helton FL, Pinheiro BT. Correlation between radiographic signs of third molar proximity with IAN. A prospective, double-blind study. Acta Cirugica Brasileiea-2013; 28:221-227.

7. Leung YY, Cheung LK. Risk factors of neurosensory deficits in lower third molar surgery: A literature review of prospective studies. Int $\mathrm{J}$ Oral Maxillofac Surg. 2011; 40:1-10.

8. M Nagaraj, Chitre AP. Mandibular third molar and inferior alveolar canal. J Maxillofac oral Surg 2009; 8:233-236.

9. Wahid A, Shah SA, Katpar S. Lingual nerve damage during third molar surgery. Pak Oral Dent Jr December 2013; 33:436-438.

10. Sharma R, Sarivasta A, Chadramal $R$, Nerve injuries related to mandibular third molar extractions. E-J of Dent, 2012; 2:78-82.

11. Bouloux GF, Steed MB, Perciaccante VJ. Complications of third molar surgery. Oral Maxillofac Sur Clin North Am. 2007; 19:117-128.

12. Meshram VS, Meshram PV, Lambade P. Assessment of nerve injuries after surgical removal of mandibular third molar: A prospective Study. Asian J of Neurosci. 2013; 29:26-32.

13. Schneider T, Filo K, Kruse AL, Locher M, Grätz KW, Lübbers HT. Variations in the anatomical positioning of impacted mandibular wisdom teeth and their practical implications. J Swiss Dental 2014; 124 (5):520-529.

14. Ardakani FE, Booshehri MZ, Azam AN Ardakani FF. Diagnostic accuracy of panoramic radiography in determining the position of impacted third molars in relation to the inferior dental canal compared with surgery. Iran J Radiol 2010; 7(2): 91-96.

15. American association of oral maxillofacial surgeons: Report of a workshop on the management of patients with third molar teeth. J Oral Maxillofac Surg 2013; $52: 1102$.
16. National Institute of Dental Research. Removal of third molars. NIH consensus development program statement 1979; November 28-30; 2:65-68.

17. Abdulai AE, Nuamah IK, Sackeyfio J, Hewlett S. Indications for surgical extraction of third molars: A hospital-based study in Accra, Ghana. Int J Med Biomed Resea 2014; 3(3):25-9.

18. Adeyemo $\mathrm{WL}$, James $\mathrm{O}$, Ogunlewe $\mathrm{MO}$, Ladeinde $\mathrm{AL}$, Taiwo OA, Olojede AC. Indications for extraction of third molars: a review of 1763 cases. Niger Postgrad Med J 2008; 15:42-6.

19. Koong B, Pharoah MJ, Bulsara M, Tennant M. Methods of determining the relationship of the mandibular canal and third molars: A survey of Australian oral and maxillofacial surgeons. Australian Dental J 2006; 51: (1):64-68.

20. Ghaeminia H, Meijer GJ, Soehardi A, Borstlap WA, Mulder J, Berge SJ. Position of the impacted third molar in relation to the mandibular canal. Diagnostic accuracy of cone beam computed tomography compared with panoramic radiography. Int $\mathrm{J}$ Oral Maxillofac Surg. 2009; 38:964-71.

21. Cheung LK, Leung YY, Chow LK, Wong MC, Chan EK, Fok $\mathrm{YH}$. Incidence of neurosensory deficits and recovery after lower third molar surgery: A prospective clinical study of $\mathbf{4 3 3 8}$ cases. Int J Oral Maxillofac Surg. 2010 Apr; 39(4):320-6.

22. Haug RH, Perrott DH, Gonzalez ML, Talwar RM. The American association of oral and maxillofacial surgeons age-related third molar study. J Oral Maxillofac Surg. 2005 Aug; 63(8):1106-14.

23. Smith WP. The relative risk of neurosensory deficit following removal of mandibular third molar teeth: The influence of radiography and surgical technique. Oral Surg Oral Med Oral Pathol Oral Radial. 2013 Jan; 115(1):18-24.

\begin{tabular}{|c|c|c|c|}
\hline \multicolumn{4}{|c|}{ AUTHORSHIP AND CONTRIBUTION DECLARATION } \\
\hline Sr. \# & Author(s) Full Name & Contribution to the paper & Author(s) Signature \\
\hline 1 & Abdul Wahid Bhangwar & $\begin{array}{l}\text { Principal Author, Data } \\
\text { collection. }\end{array}$ & 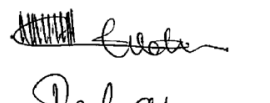 \\
\hline 3 & Hira Fatima & Manuscript Designing. & \&o. \\
\hline 4 & Salman Shams & $\begin{array}{l}\text { Data collection, Discussion \& } \\
\text { Proof read. }\end{array}$ & \\
\hline
\end{tabular}

